\title{
Defining and Acting on Global Health: The Case of Japan and the Refugee Crisis
}

\section{Claire Leppold $^{{ }^{*}}$, Akihiko Ozaki ${ }^{2}$, Yuki Shimada ${ }^{3}$, Tomohiro Morita ${ }^{4}$, Tetsuya Tanimoto ${ }^{5}$}

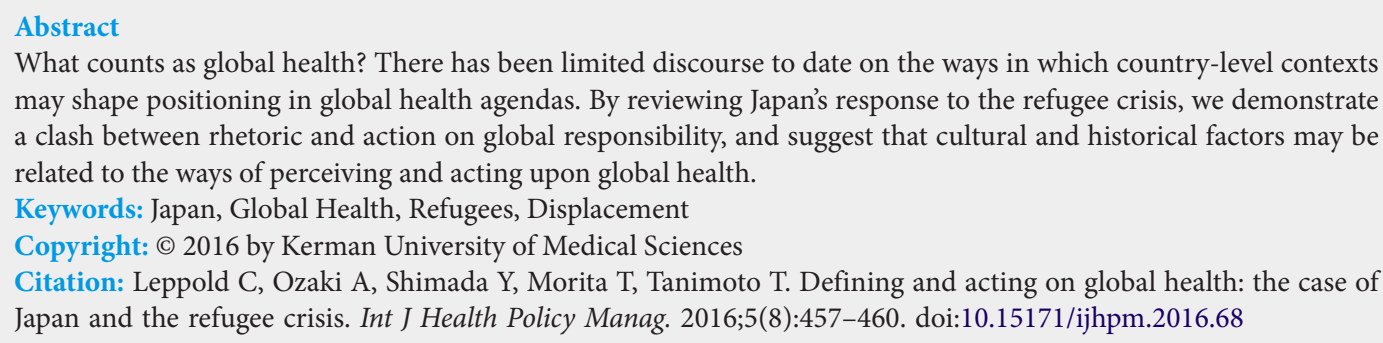

\author{
Article History: \\ Received: 2 March 2016 \\ Accepted: 28 May 2016 \\ ePublished: 31 May 2016 \\ *Correspondence to: \\ Claire Leppold \\ Email: cleppold@gmail.com
}

\section{Introduction}

The concept of 'global health' now predominates. With goals that reach beyond national borders, countries have been brought together to better the health of all. ${ }^{1}$ However, perception of what constitutes a global health issue, and subsequent action, differs between countries. Through highlighting a case of differing rhetoric and action in Japan, this paper suggests that cultural and historical contexts may shape conceptualization of, and action on, global health.

\section{Statement and Action}

The Prime Minister of Japan, Shinzo Abe, has recently published a paper about global health ${ }^{2}$; a rare example of a politician attempting to directly engage with the subject. Japan's commitment to a more peaceful and healthy world was underlined, and an emphasis was placed on global responsibility, with Abe stating that "health issues are not purely the domestic concerns of individual countries." ${ }^{2} \mathrm{We}$ strongly agree with the importance of a global commitment to health. However, do the political actions of Japan fully support these statements?

The refugee crisis is resulting in millions displaced with significant health burdens. ${ }^{3,4}$ While there has not been explicit international agreement to categorize the crisis as a global health issue, it can be strongly presented as such through the perspective of human rights ${ }^{3,5,6}$ or human security, ${ }^{7,8}$ and calls have been made for the international community to support the health and asylum of refugees. ${ }^{3,4}$ However, Japan's response to this issue remains limited to financial support. In 2014, only 11 of 5000 applicants (0.2\%) were accepted for asylum in Japan. ${ }^{9}$ There was no significant increase in 2015 , with 27 of 7586 applicants $(0.3 \%)$ accepted. ${ }^{10}$ The United Nations Children's Fund (UNICEF) has urged Japan to accept more refugees for asylum, to no avail. ${ }^{11}$ Instead, there has been political insistence that domestic problems affecting Japan's own people must be addressed before accepting refugees, ${ }^{11} \mathrm{a}$ statement which directly conflicts with the concept of health as a global responsibility. The engagement of a Prime Minister with global health is admirable, and we applaud Abe for addressing this topic. However, the chasm between statement and action on global responsibility for health observed in this case provokes inquiry of what 'counts' as a global health; a question to which the answer is likely to differ depending on the conceptual framework it comes from.

\section{Japan's Global Health Positioning}

It is crucial to remember that there is not one set definition of global health, ${ }^{12,13}$ and with the intrinsic diversity of its actors, it may be diversely interpreted and acted upon based on the contexts, structures and politics of each body involved. Japan is a particularly interesting country in terms of health, with one of the highest life expectancies in the world and a universal healthcare system. The legacy of Japan's rise from defeat in World War II to a country with high population health standards is a celebrated narrative $\mathrm{e}^{2,14}$ and the movement towards the egalitarian care of all people encompassed in the 1961 creation of universal health coverage $e^{15,16}$ is a history that could position Japan to recognize the need for egalitarian care internationally as well. Indeed, Japan has made notable financial donations to health initiatives in development work. ${ }^{14,17}$ Japan's G7 presidency from April 2016 has been recognized as an additional opportunity to use the country's experiences to promote global health, with a strong focus on health system architecture and advocating for universal health coverage. ${ }^{2}$ A notable aspect of Japan's participation in global health is that there has been a dominating focus on financial assistance, ${ }^{14,17,18}$ and 'outputs' in global health have been measured as monetary amounts donated. ${ }^{14}$ This background comes to surface in the Japanese response to the refugee crisis. In order to understand this approach, we argue that further discussion is warranted on how country-level contextual factors may influence perspectives and actions on global health. 


\section{Behind Policy}

Surprisingly little discussion has been undertaken on the ways in which history and culture may backlight interactions with global health. Traditional conceptualization of and contact with the 'outside' are topics that may be particularly relevant in this regard, as we suggest in Japan's case. Homogeneity has been professed as a key characteristic of the country from the times of the Nihonjin writings, which put forth an ideology of the unique ethnicity and culture that comprise Japaneseness. ${ }^{19}$ In contrast to this unique Japaneseness, the role of the 'other' has also been written about extensively. ${ }^{20}$ Soto and uchi, translating to 'outside' and 'inside,' are fundamental concepts often presented in anthropology work on Japan ${ }^{20,21}$ in terms of the ways these words are used to classify human relationships and positionality. Relationships between Japanese people in Japan can be broken into in-group uchi and out-group soto categories, as well as relationships between Japanese people and foreigners; the two characters that compose the word 'foreigner' (gaijin) are outside (soto) and person (hito). ${ }^{20}$ These classifications may also refer to Japan as a country (uchi) and the rest of the world (soto). ${ }^{20}$ Anthropologists have noted that while long-established uchi and soto concepts may be helpful to promote a national Japanese identity, movements toward globalization may 'pose a threat' to the ideology of Japaneseness by questioning national homogeneity, the $u$ chi. ${ }^{20}$ Purity is another concept which can be intertwined with $u c h i$ and soto, and has been discussed at length in relation to the cultural history of uchi Japan in terms of the bloodline composition of the nation..$^{22,23}$ Although one may receive naturalized citizenship, the belief that blood is the only factor that can qualify true Japaneseness has been discussed at length, with Japanese blood becoming the condition for nationality, or belonging in Japan. ${ }^{22,23}$ On a fundamental level, the perception of the $u c h i$ (inside) as harmonious and cohesive in contrast to the soto (outside) ${ }^{20}$ is one which may pose difficulties in the era of globalization, and more specifically in terms of Japan's place in global (health) agendas.

While these issues might at first glance appear tangential to the problem of policy and management, their discussion is imperative to furthering understanding of the mechanics behind Japan's global health participation. The ideology of homogeneity has been noted previously as a background to Japan's restrictive immigration and refugee asylum policies, ${ }^{24}$ and it is possible that this, in addition to 'othering, are factors that could influence Japan's global actions as well.

For instance, Japan ratified the Refugee Convention in 1981, yet has faced enormous criticism for not adopting the actual principles of the Convention into Japanese law. ${ }^{24}$ Japan's refugee-related policies and procedures have been criticized for bureaucracy, lack of transparent procedures and for deporting individuals recognized as refugees by the United Nations High Commissioner for Refugees (UNHCR). ${ }^{25}$ While asylum seekers wait for decisions on whether they will be recognized as refugees or not, they can be granted temporary permission to stay in Japan, yet this does not automatically allow them the right to work. ${ }^{25}$ Those who are not granted permission are regarded as overstayers during the appeal period, which can last for up to two years, during which they have no legal status, right to work, right to access national healthcare or other types of welfare. ${ }^{25}$ The lack of acceptance of refugees into Japan has resulted in international criticism for the country's chequebook approach to assistance, and the reality faced by asylum seekers who do make it into Japan has been described 'destitute' due to the inaction and negligence of authorities. ${ }^{24}$ In 2007, Dean and Nagashima found that "when compared to the rates of other G7 countries, Japan's share of the Convention refugee recognition cases is statically almost zero," 24 and we could find no evidence to suggest that this situation has changed since then.

Abe's statements on the necessity of global responsibility for the health of all people are distressing in comparison with Japan's restricted acceptance of refugees for asylum, and the limitations they face after arriving to Japan. It may not be possible to directly prove links between cultural or historical factors with policy issues, such as soto and uchi conceptualization with the treatment of refugees, however, we are not the first to suggest they are related. One striking statement was made by Sadako Ogata, previous UNHCR High Commissioner, in 2002. After stepping down from her position, Ogata publically remarked that "the small number of refugees accepted each year by Japan raises the question of whether Japan has fully understood and tried to practice the spirit and values embodied in the Refugee Convention. One reason that Japan's exclusionary asylum policy is like this may be because of our prejudice and discrimination against foreigners which is based upon the mono-ethnic myth. However, in the era of globalization we cannot hold on to that illusion. We need to overcome our insular spirit and xenophobia and consider the world's problems as our own and not those of somebody else." ${ }^{26}$ Ogata's statement is significant in that the claim to global responsibility echoes Abe, yet simultaneously references prejudice, discrimination, xenophobia, and the tendency towards homogeneity as issues to overcome. We urge the Japanese government to take account of these points. Being a global health leader or achieving the global responsibility that Abe advocates requires fundamental consideration of what 'otherness' may mean in relation to Japan's position in the world and in global health at large.

\section{To the Future}

This case from Japan is one of a mismatch between rhetoric on global responsibility for the health of all people and action on the refugee crisis, a divide which opens up questions relevant to broader global health discussion. Values, cultural beliefs and historical legacies are all factors that may differ between countries, yet significantly contribute to the ways in which global health is defined and acted upon. We do not intend to dispense a harsh commentary on Japan, but rather to promote discussion on perception and participation in global health, and how agreement to agendas and action may not align between countries. Prejudice, discrimination and 'othering' are issues to be overcome for Japan's pragmatic engagement with the refugee crisis, and may be of relevance to roles played in larger global health agendas as well.

In May 2016, it was announced that over the next five years, Japan will allow 150 Syrians into the country; however, they will be accepted as exchange students, not as refugees. ${ }^{27}$ This move has been observed as an attempt to ward off criticism on Japan's refugee policies. ${ }^{27}$ However, the strategy 
of accepting refugees as exchange students directly avoids the root problems which Japan is criticized for: low acceptance of asylum applications and insufficient treatment of refugees in the country. ${ }^{24,25}$ While political recognition of the refugee crisis is encouraging, the proposed measures reinforce the 'visiting' status of refugees.

In order to improve refugee policy, as well as cultivate the environment that will meet the 150 Syrian students and other refugees in Japan, we suggest the following points for engagement and action. First, we urge Japan to work towards implementing laws that support the Refugee Convention; in particular, follow-through on the agreement to refugee protection through asylum. ${ }^{24}$ Second, we advocate for awareness that refugee health cannot be accomplished through asylum or access to healthcare alone. Evidence for health impacts of the socio-political context that refugees encounter is overwhelming, ${ }^{28}$ highlighting the need to address the daily experiences that refugees may face in Japan. In this respect, we advocate for increased public awareness of diversity and discrimination, which could be accomplished through expanded platforms for discourse including educational opportunities for the general public. Diversity awareness is a minimum baseline to creating an environment of dignity and integrity for refugees that arrive in Japan. The above points can moreover be argued to hold the potential to further Japan's participation in global health; acceptance and care for refugees are steps toward the global responsibility that Abe references. ${ }^{2}$

We conclude with the intention to prompt discussion on how not only Japan, but all countries may perceive and act on global health in ways shaped by cultural and historical factors. The influence of country-level contexts calls for understanding, in order to improve organization and engagement in global agendas, and ultimately achieve global health goals.

\section{Acknowledgements}

There is no research funding or financial support to report. We thank Dr. Sudeepa Abeysinghe for her constructive feedback on this paper.

Ethical issues

Not applicable.

\section{Competing interests}

Authors declare that they have no competing interests.

\section{Authors' contributions}

$\mathrm{CL}, \mathrm{AO}$, YS, and TM conceptualized the paper. CL and TT wrote the manuscript, and all authors contributed to revision.

\section{Authors' affiliations}

'Department of Research, Minamisoma Municipal General Hospital, Fukushima, Japan. ${ }^{2}$ Department of Surgery, Minamisoma Municipal General Hospital, Fukushima, Japan. ${ }^{3}$ Department of Neurosurgery, Minamisoma Municipal General Hospital, Fukushima, Japan. ${ }^{4}$ Department of Internal Medicine, Soma Central Hospital, Fukushima, Japan. ${ }^{5}$ Department of Internal Medicine, Jōban Hospital, Tokiwa Foundation, Fukushima, Japan.

\section{References}

1. UNDP Support to the Implementation of the 2030 Agenda for Sustainable Development. United Nations Development Programme (UNDP) website. http://www.undp.org/content/undp/ en/home/librarypage/sustainable-development-goals/undpsupport-to-the-implementation-of-the-2030-agenda/. Accessed
May 21, 2016.

2. Abe S. Japan's vision for a peaceful and healthier world. Lancet. 2015;386:2367-2369. doi:10.1016/S0140-6736(15)01172-1

3. Gostin LO, Roberts AE. Forced migration: the human face of a health crisis. JAMA. 2015;314:2125-2126. doi:10.1001/ jama.2015.14906.

4. Adapting to migration as a planetary force. Lancet. 2015;386:1013. doi:10.1016/S0140-6736(15)00190-7

5. Morabia A, Benjamin GC. The Refugee Crisis in the Middle East and Public Health. Am J Public Health. 2015;105(12):24052406. doi:10.2105/AJPH.2015.302929

6. Rousseau C, ter Kuile S, Muňoz M, et al. Health Care Access for Refugees and Immigrants with Precarious Status: Public Health and Human Right Challenges. Can $J$ Public Health. 2008;99(4):290-292.

7. Kupferschmidt K. Refugee crisis brings new health challenges. Science. 2016;352(6284):391-392. doi:10.1126/ science.352.6284.391

8. Chen L, Narasimhan V. Human security and global health. J Hum Dev. 2003;4(2):181-190. doi:10.1080/1464988032000087532

9. Activity Report. Japan Association for Refugees website. https:// www.refugee.or.jp/jar/report/2015/03/12-0000.shtml. Accessed May 26, 2016. (Japanese Language).

10. Takenaka K, Wildon T, Funakoshi M, et al. Asylum seekers in Japan reach record 7,586 in 2015. Reuters. January 23, 2016. http://www.reuters.com/article/us-japan-immigrantsidUSKCNOV10E7. Accessed May 26, 2016.

11. UNICEF chief urges Japan to open its doors to more refugees. The Japan Times. October 18, 2015. http://www.japantimes. co.jp/news/2015/10/18/national/politics-diplomacy/unicef-chiefurges-japan-open-doors-refugees/\#.VmqsM781p8V. Accessed May 26, 2016.

12. Rowson M, Willott $C$, Hughes $R$, et al. Conceptualising global health: theoretical issues and their relevance for teaching. Global Health. 2012;8(1):36. doi:10.1186/1744-8603-8-36

13. Koplan JP, Bond TC, Merson MH, et al. Towards a common definition of global health. Lancet. 2009;373(9679):1993-1995. doi:10.1016/S0140-6736(09)60332-9

14. Llano R, Kanamori S, Kunii O. Re-invigorating Japan's commitment to global health: challenges and opportunities. Lancet. 2011;378(9798):1255-1264. doi:10.1016/S01406736(11)61048-9

15. Tsuchida T. 50 years of universal health care (Japanese language). Social Security Research Quarterly. 2011;47:3.

16. Ikegami $\mathrm{N}$, Yoo BK, Hashimoto $\mathrm{H}$, et al. Japanese universal health coverage: evolution, achievements, and challenges. Lancet. 2011;378(9796):1106-1115.

17. Ravishankar N, Gubbins P, Cooley RJ, et al. Financing of global health: tracking development assistance for health from 1990 to 2007. Lancet. 2009;373(9681):2113-2124. doi:10.1016/S01406736(09)60881-3

18. Takahashi K, Kobayashi J. Lessons from the field count more than ever: the new era of global health. Trop Med Health. 2015;43(4):243-245.

19. Goodman R. Making Majority Culture. In: Robertson J, ed. A Companion to the Anthropology of Japan. Malden: Blackwell Publishing; 2005:59-72.

20. Creighton M. Soto Other and Uchi Others: Imaging Racial Diversity, Imagining Homogeneous Japan. In: Weiner M, ed. Japan's Minorities: The Illusion of Homogeneity. London: Routledge; 1997:211-38.

21. Bachnik J. Uchi/Soto: Challenging our conceptualizations of self, social order, and language. In: Bachnik J, Quinn C, eds. Situated Meaning: Inside and Outside in Japanese Self, Society, and Language. Princeton: Princeton University Press; 1994:3-37.

22. Robertson J. Blood talks: Eugenic modernity and the creation 
of new Japanese. Hist Anthropol. 2002;13(3):191-216. doi:10.1080/0275720022000025547

23. Robertson J. Hemato-nationalism: The Past, Present, and Future of "Japanese Blood". Med Anthropol. 2012;31(2):93-112. doi:10.1080/01459740.2011.624957

24. Dean M, Nagashima M. Sharing the burden: the role of government and NGOs in protecting and providing for asylum seekers and refugees in Japan. J Refug Stud. 2007;20(3):481508. doi:10.1093/jrs/fem009

25. Flowers PR. Failure to Protect Refugees? Domestic Institutions, International Organizations, and Civil Society in Japan. J Jpn Stud. 2008;34(2):333-361. doi:10.1353/jjs.0.0028

26. Ogata S. Asylum policy reform: Embracing a literal perspective.
Message to the Japan Federation of Bar Associations Symposium on Japan's Refugee Protection System, Tokyo. http://www.unhcr.or.jp/html/protect/pdf/nov02ms_ogata.pdf. Accessed May 20, 2016. Published November 16, 2002.

27. Mie A. Japan to take in 150 Syrians as exchange students after criticism of harsh refugee policy. The Japan Times. May 20, 2016. http://www.japantimes.co.jp/news/2016/05/20/national/ japan-take-150-syrians-exchange-students-criticism-harshrefugee-policy/\#.VOP2FOTElqt. Accessed May 24, 2016.

28. Parkinson SE, Behrouzan O. Negotiating health and life: Syrian refugees and the politics of access in Lebanon. Soc Sci Med. 2015;146:324-331. doi:10.1016/j.socscimed.2015.10.008. 